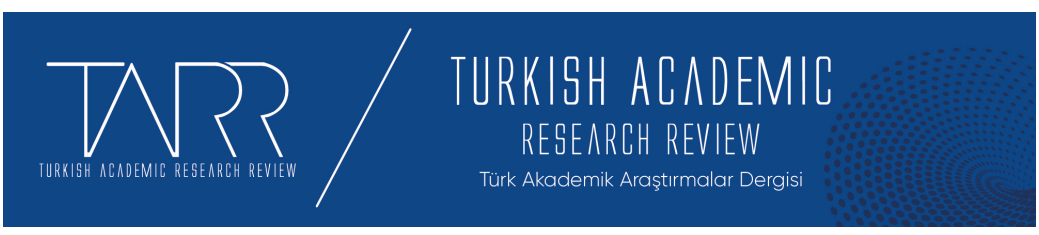

e-ISSN: 2602-2923 Yil/Year: $2021 \quad$ Cilt/Volume: 6 Sayı/Issue: 2

\title{
Hinduizm ve İslam Arasında: Şirdi Sai Baba Örneği
}

Between Hinduism and Islam: Shirdi Sai Baba Example

\section{Arzu YILDIZ}

Arş. Gör., Ankara Üniversitesi İlahiyat Fakültesi, arzuyildiz2484@gmail.com, Orcid ID: 00000001-5286-1089

\begin{tabular}{r|l} 
Makale Bilgisi & Article Information \\
Makale Türü - Article Type & Araştırma Makalesi / Research Article \\
Geliş Tarihi - Date Received & 26 Mart / March 2021 \\
Kabul Tarihi - Date Accepted & 23 Haziran / June 2021 \\
Yayın Tarihi - Date Published & 25 Haziran / June 2021 \\
Yayın Sezonu & Nisan - Mayıs- Haziran \\
Pub Date Season & April - May - June
\end{tabular}

Atıf / Cite as: Yıldız, A. (2021). Hinduizm ve İslam Arasında: Şirdi Sai Baba Örneği/Between Hinduism and Islam: Shirdi Sai Baba Example. Turkish Academic Research Review, 6 (2), 544-565. Retrieved from https://dergipark.org.tr/tr/pub/tarr/issue/62824/903914

Intihal / Plagiarism: Bu makale, en az iki hakem tarafından incelenmiş ve intihal içermediği teyit edilmiştir. / This article has been reviewed by at least two referees and confirmed to include no plagiarism. https://dergipark.org.tr/tr/pub/tarr

Copyright (C) Published by Mehmet ŞAHİN Since 2016- Akdeniz University, Faculty of Theology, Antalya, 07058 Turkey. All rights reserved.

Turkish Academic Research Review - Türk Akademik Araştırmalar Dergisi 


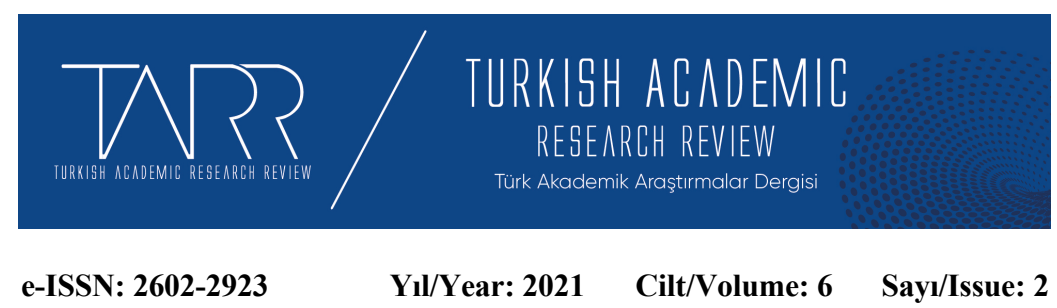

Hinduizm ve İslam Arasında: Şirdi Sai Baba Örneği

Arzu YILDIZ

\title{
Öz
}

Şirdi Sai Baba, Hint din, kültür ve medeniyetinin özgün bir örneğini oluşturur. Sai Baba'nın doğumu, dini menşei ve kastı belli olmamakla beraber o, ölümünden önce ve sonra pek çok din mensubunu peşinden sürüklemiş hem Müslümanlar hem de Hindular tarafından kendi dinlerinin mensubu kabul edilmiştir. $\mathrm{O}$ ise bu hususa hiçbir zaman açıklık getirmemiştir. Müslümanların gözünde kerametler sergileyen bir evliya fakîr, Hindular için ise kendilerine rehberlik edip onları kurtuluşa ulaştırmak için uğraşan bir guru hatta yeryüzüne inerek mucizeleriyle adanmışlarının yardımına koşan bir tanrıdır. Onun öğretileri Hinduizm ve İslam'a ait öğelerin bir birleşiminden müteşekkildir. Dine ya da kasta dayalı bir ayrım yapmayan Sai Baba'nın maksadı vaaz vermenin ötesinde sevgi ve doğrulukla insanlığ 1 ikaz etmek ve Tanrı'ya ulaşmalarını sağlamaktır.

Her ne kadar Sai Baba’nın Müslüman kimliği günümüzde arka planda kalmış olsa da meşhur söz ve tavsiyeleri onun İslam'la bağını ortaya koymaktadır. Hatta vefatından yaklaşık on yıl öncesine kadar İslami kimliği çok daha belirgindir denilebilir. O, İslam dinine aşina olan bir Hindu'dan ziyade Hinduizm'e ait öğelere aşina, Hindu adanmışları olan bir Müslüman fakîr görünümündedir. Vefatından önceki son yıllarında ise kendisine tapınılmasına izin vermiş, karma, samsara gibi kavramları daha sık kullanmıştır. Ölümünü takip eden yıllarda Sai Baba'nın ünü Hindistan sınırlarını aşmış, bir diğer meşhur Hintli dini figür olan Sathya Sai Baba'nın da katkısıyla o, dünya çapında tanınmıştır. Günümüzde Şirdi, Sai Baba’nın taraftarları için bir hac yeri, mezarı, hayatını geçirdiği cami ve kendisinden kalan birkaç eşya ziyaretler sırasında hürmet gören kutsal emanetlerdir. Sai Baba'ya adanmış çeşitli dini ritüeller Hindu dini geleneği çerçevesinde halen tüm canlılığıyla sürdürülmeye devam etmektedir.

Anahtar Kelimeler: Şirdi Sai Baba, İslam, Hinduizm, Fakîr, Guru

\section{Between Hinduism and Islam: Shirdi Sai Baba Example}

\begin{abstract}
Shirdi Sai Baba is a geniune example of Indian religion, culture and civilization. Although Sai Baba's birth, religion and caste were unknown, before and after his death, he dragged many members of different religions after him and was accepted by both Muslims and Hindus as a member of their religion. However, he never clarified this issue. He is a faqir saint who exhibits miracles(karamats) in the eyes of Muslims whereas for Hindus he is a guru who strives to guide them and lead them to salvation, even a god who descends to the earth and helps his devotees with his miracles. His teachings are a combination of elements belonging to Hinduism and Islam. The purpose of Sai Baba, who does not make any discrimination based on religion or caste,
\end{abstract}

Turkish Academic Research Review - Türk Akademik Araştırmalar Dergisi 
was to warn mankind with love and righteousness beyond preaching and to enable them to reach God.

Although Sai Baba's Muslim identity has remained in the shadows today, his famous words and preaches reveal his ties to Islam. In fact, it can be said that his Islamic identity was much more evident until about ten years before his death. Rather than a Hindu familiar with Islam, he appears to be a Muslim faqir with Hindu devotees whose familiar with elements of Hinduism. In the last years before his death, although, he allowed himself to be worshiped and used concepts such as karma and samsara more often. In the years following his death, Sai Baba's fame went beyond the borders of India and with the contribution of another famous Indian religious figure Sathya Sai Baba, he became known worldwide. Today, Shirdi is a pilgrimage site for the devotees of Sai Baba, and his tomb and the mosque where he spent his life, also a few of his remains are relics venerated during visits. Various religious rituals dedicated to Sai Baba still continue to be carried out with all their vitality within the framework of the Hindu religious tradition.

Keywords: Shirdi Sai Baba, Islam, Hinduism, faqir, guru

\section{Structured Abstract}

As a unique example of religious diversity, the Indian continent has hosted many religions, religious movements and personalities throughout history. Sai Baba is also one of the famous example of the numerous examples of India's social, cultural and religious diversity. We can state that he is a remarkable and syncretic religious figure who has managed to gain a unique place in the rich ascetic-mystic tradition of India, with his unknowns, miracles, and unique synthesis and practices between the two religions.

Sai Baba's life can be considered in two parts, before and after Shirdi, where he came and settled at a young age. It can be said that the life of Sai Baba, who was born in the middle of the 19th century and lived until the beginning of the 20th century, as a relatively contemporary religious figure, is full of unknowns. As a matter of fact, Baba's birth date, place, family, caste and religion, even his real name is not known for certain. The information about his life before Shirdi which is a small town located in today's Maharashtra State of India, is extremely limited and contradictory. We learn about his life after he settled in Shirdi, mostly from writings and works that include the experiences and miracles of his Brahmin Hindu devotees, who wrote about him in hagiographic style and conveyed his teachings, discourses, behavior and attitudes from their own observations and perspectives.

When he came to Shirdi, he looked like a young faqir in his $20 \mathrm{~s}$. He used to roam around in a white robe called kafni, typical of Muslim ascetics, a cloth on his head that he never took off, a short staff, a tin container in which he kept the liquids he begged, the clay pipe he used for smoking tobacco, and the brick that he never left with him until it broke near his death.

Sai Baba has taken up an old and abandoned mosque in Shirdi as his abode. He lived in this mosque, which he called Dwarakamai, until his death, and carried out most of his religious activities here. In the courtyard of the mosque, he used to burn a sacred fire that he never extinguished. His words and prayers contains both Islamic and Hindu symbols and elements. The doors of Dwarakamai were open to people of all religions, creeds, genders and castes.

When Sai Baba came to Shirdi, he acted as a local doctor with the herbs he collected, cheap drugs and even snake venom, and became a healer. Later, herbs or medicines disappeared, and they were replaced by ashes (udhi) obtained from the 
sacred fire (dhuni), which he kept constantly burning. He gave this ash to those who came to visit him without taking any money, and the patients hoped to be healed by applying or consuming this ash on their aching body parts and wounds. Those who came to visit were definitely given this ashes when leaving Shirdi. It was believed that this ash was good for all kinds of disease, scorpion and snake bites, preventing epidemics, bringing abundance, protecting from the evil eye and bringing luck. Miracles are attributed to Shirdi Sai Baba such as healing the sick, being in more than one place at the same time, preventing epidemics, flying in the air, exorcism, entering samadhi at any time, creating from nothing, knowing and controlling the future, reading minds, controlling people's thoughts, resurrecting the dead.

It is seen that he did not show any interest in the material world, property, possessions or even family life, and considers self-knowledge and reaching God with love, patience and tolerance as his sole goal. This attitude of his shows that he is no different from other Sufis whose lives and various stories are still being told today, and it also resembles Hindu ascetics who chose to reach God as their only goal by refraining from worldly affairs.

Sai Baba choosed to remain indifferent to questions about himself, including his religious origin. However, while he was rejecting questions about whether he was a Muslim or a Hindu, he did not aim to attract supporters or to present a new religious view. This situation has also manifested itself in many of his discourses and behaviors. For some his views are the words of a crazy faqir and for others the word of God.

While Sai Baba's inclusion of elements belonging to both Islam and Hinduism in his sermons and discourses ensures that he is embraced by the followers of both religions, his non-exclusive attitude and his encompassing religious principles have a great role in the fact that people of all religions, ages, genders and castes see him as a guide.

\section{Giriş}

Hindistan insanlığın en eski medeniyet merkezlerinden biridir. Ortaya çıkarılan bulgular ışı̆̆ında İndus vadisi üzerinde kurulmuş ilk düzenli şehir devletleri ve hatta daha öncesine dayanan dönemin inanç ve sembollerinin günümüzde bu coğrafyada varlık gösteren Hinduizm başta olmak üzere din ve inanışların nüvesini oluşturduğu dile getirilebilir (Bu konuda daha ayrıntılı bilgi için bkz. Sharma, 2017). Günümüze kadar ulaşmış olan bu zenginlik ve birikim hala canlılığını koruyarak devam etmekte ve siyasetten felsefeye, edebiyattan tıbba akla gelebilecek hemen her konuda kendini hissettirmektedir. İnsanlık tarihi kadar köklü bir konu olan dinin ise bu durumdan payını almadığını düşünmek mümkün değildir. Hinduizm, Buddizm, Caynizm, Sikhizm gibi Hint dinlerinde ve bölgeye sonradan gelen Zerdüştlük, Hıristiyanlık ve İslam dinlerinin bölgedeki yaşanış ve algılanışında bu zenginlik kendini gösterir.

Müslümanlarla ilk temasların miladi yedinci asırda, Müslümanların bölgeye kalıcı yerleşimlerinin ve etki alanlarını genişletmelerinin ise on birinci asırda başladığı görülür (Kutlutürk 2019: 7). Bölgeye yerleşen Müslümanlar, din adamları ve tasavvuf ehli kişiler vasıtası ile yerli halktan İslamiyet'i kabul edenlerde olmuştur. 
Temel inanç ve akidelerinde birbirinden tamamıyla ayrılan bu iki dinin mensuplarının birbirleriyle etkileşime geçmeleri, birbirlerine karşı olumlu ya da olumsuz yönde tutum ve görüşlerin şekillenmesine de sebebiyet verdiği tarihi bir gerçeklik olarak karşımıza çıkmaktadır. Nitekim inanışların belirli hususlarda birbirlerini etkilemeleri kaçınılmazdır.

Dinler arasındaki sınırların berraklığını kaybettiği durumlarda dini bir sembol, eylem, ayin ya da emir başka bir dinin inananlarınca benimsenebilir. Hatta yeni bir din, mezhep, tarikat olarak tarih sahnesinde boy gösterebilir. Zaman zaman da dini bir lider önderliğinde insanları peşinden sürükleyen senkretik yeni bir inanışın çıkması da tarih boyunca pek çok kez örneklerinin görüldüğü bir durumdur. Bu açıdan bakıldığında Hindu mistisizmi ve İslam tasavvuf anlayışının Müslümanların Hint topraklarına kademeli olarak gelişi ve ardından kalıcı devletlerin kurulmasıyla bu iki topluluğun karşıllklı ilişki içine girdikleri ve bunun sonucunda birbirlerini etkilediklerini söyleyebiliriz (Bu konuda daha ayrıntılı bilgi için bkz. Kutlutürk, 2019). Buna bağlı olarak her iki inanç sistemine ait umdeleri kucaklayan ve her iki inancın müntesiplerince de hürmet gören pek çok şahsiyetin tarih sahnesinde boy göstermiş olduğunu görürüz. Sai Baba da bu şahsiyetlerin görece güncel ve özgün bir örneğini oluşturur.

Sai Baba Müslümanlarca Allah dostu bir mürşid ve evliya olarak kabul edilirken Hindularca ruhani bir lider, guru ve bununda ötesinde ahir zamanda insanları kurtarmak için dünyaya gelmiş, Hindu panteonunun Vişnu ve Şiva gibi tanrılarının avatarası, yani tanrının dünya üzerinde bedenlenmesi olduğu kabul edilir. Onu, hem tevhid inancının hâkim olduğu İslam dini mensuplarının hem de kalabalık panteonuyla Hinduların kendilerine rehber kabul ettikleri bir şahsiyet olarak görmeleri dikkate şayandır. Şirdi Sai Baba'yı ilginç kılan ve araştırmamıza konu olarak seçmemize sebep olanda budur. Bu çalışmada hem Hindu hem Müslümanlar tarafindan benimsenen Sai Baba'nın hayatını, mucizelerini, ona adanan ibadet ve ayinleri, kendine has söz ve davranışlarını ele alarak incelemeye gayret edeceğiz.

\section{Sai Baba'nın Hayatı}

Tarihsel kişiliği, öğretileri ve yaşantısı kadar ölümünden sonra da giderek artan ünüyle hem Müslümanlar hem Hindularca sahiplenilen Sai Baba Parsi, Sikh ve hatta Hıristiyanların büyük rağbet gösterdiği, Hindistan başta olmak üzere birçok ülkede tapınakları olan bir dini şahsiyettir (McLain 2011: 29-30). 19. asrın ortalarında doğup, 20. asrın başlarına kadar yaşamış ve görece çağdaş kabul edilebilecek bir dini figür olarak karşımıza çıkan Sai Baba'nın hayatı bilinmezlerle doludur denilebilir.

Turkish Academic Research Review - Türk Akademik Araştırmalar Dergisi https://dergipark.org.tr/tr/pub/tarr 
Nitekim Baba'nın doğum tarihi, yeri, ailesi, kastı ve dini hatta gerçek ismi dahi kesin olarak bilinmemektedir. Günümüzde Hindistan'ın Maharaştra Eyaleti sınırlarında yer alan küçük bir yerleşim yeri ${ }^{1}$ olan Şirdi'den önceki hayatı hakkındaki bilgiler son derece sınırlı ve çelişkilidir (Rigopoulos 1993, 3). Şirdi’ye yerleşmesinden sonraki hayatını ise ekseriyetle onun hakkında hagiyografik (evliyaname) tarzda eserler kaleme alarak öğreti ve söylemlerini, davranış ve tutumunu kendi gözlemleri ve bakış açılarından aktaran özellikle Brahmin Hindu kökenli adanmışlarının onunla ilgili tecrübelerini ve mucizelerini içeren yazılardan, eserlerden ediniyoruz. ${ }^{2}$ Bunlar genellikle onun davranışlarını ve söylemlerini yazarın dini anlayışı çerçevesinde ele alıp yorumladığı eserler olarak karşımıza çıkmaktadır. Bu yüzden tamamen tarafsız ve objektif eserler olduklarını söylemek güçtür. Her ne kadar bilinmezlerle dolu olsa da elimizdeki verilerden hareketle onun hayatını ele almaya gayret edeceğiz.

\section{Şirdi’den Önceki Hayatı}

$\mathrm{Bu}$ dönem hakkında bilinenler son derece kısıtlı ve çelişkili olmakla beraber Sai Baba'nın dini görüş ve anlayışının şekillendiği, hayatının en önemli evresi olduğunu söyleyebiliriz. Sai Baba ismi, Şirdi’ye 1858 yılında kalıcı olarak gelişinden sonra kendisine verilmiştir. Asıl adının Haribhau Bhusari (Kher 2000, 15) olduğunu iddia edenler mevcuttur ancak bu daha ziyade ona Hindu bir kimlik kazandırma çabası olarak değerlendirilebilir. Sai lakabı kendisine ilk defa 1858 yılında bir düğün alayıyla Şirdi’ye geldiği sırada bölgedeki küçük bir tapınak olan Khandoba ${ }^{3}$ mandirinin rahibi olup Sai Baba’nın ilk adanmışı olarak kabul edilen ve Baba hakkında yazılan eserlerde kendisinden çokça alıntı yapılan Mahlsapati tarafından verilmiştir. Şirdi’ye gelen bu genç fakîr'e Mahlsapati “Ya Sai (Hoş geldin Sai)” diye seslenmiş bundan sonra o, Sai adıyla bilinmiştir (Dabholkar 2018, 24). Sai

\footnotetext{
${ }^{1}$ Bazı eserlerde köy bazılarında ise kasaba olarak geçen Şirdi, günümüzde binlerce insanın ziyaret ettiği bir ziyaret ve hac yeri olmakla beraber Sai Baba'nın buraya yerleştiği dönemde yani 1850'li yıllarda son derece küçük bir yerleşim yeriydi. 1918'de Baba'nın vefatı zamanında 200 hanelik bir kasaba durumundaydı (Shinde 2016, 132-135).

2 Baba'nın takipçi ve adanmışlarınca kaleme alınmış eserlerden birkaçı oldukça önemlidir. Özellikle Sai Baba'nın izni ile adanmışlarından Govind Ragunath Dabholkar'ın Baba hayattayken kaleme almaya başladığı ve 1929 yılında basılan eseri Sri Sai Satcharita ön plana çıkmaktadır. Bu eser Nagesh Vasudev Gunaji tarafından İngilizceye çevrilmiştir. Eser katı bir Brahmin kökenden gelen yazarının bakış açısını yansıtmakta ve Sai Baba'yı ve davranışlarını Hindu bakış açısı ile yorumlamaktadır. Buna karşılık Müslüman bir fakîr olan adanmışı Abdül'ün Sai Baba'nın öğretilerini ve anılarını kaleme aldığı not defteri ise ayrı bir eser olarak basılmamış ve Hindu takipçilerince çok rağbet görmemiştir. Sai Baba'nın Müslüman Sufi gelenekten geldiğini dile getiren batılı araştırmacı Marriam Warren bu defterin çevirisine Unraveling The Enigma Shirdi Sai Baba In The Light Of Sufism adlı eserinde bir bölüm olarak yer vermiştir.

3 Maharaștra bölgesinde yerel halkın tapındı ğı, Șiva'nın meşhur bir avatarası olan Tanrı Khandoba hem Cain hem Hindu geleneklerinde kendine yer edinmiştir. Eşlerinden birinin de Müslüman olduğuna inanılan Khandoba'nın bazı heterodoks Müslüman gruplar da dahil olmak üzere her kasttan inananının olduğu dile getirilir (Sontheimer 1989, 325-327).
} 
kelimesinin Farsça "aziz" demek olan ve Müslüman asketikler için kullanılan “sa'ih"ten geldiğini söyleyenler olduğu gibi (Bharucha1984, 2; Warren 2009, 32; Rigopoulos 1993, 3) Sanskrit kökenli svami kelimesinden geldiğini iddia edenler de mevcuttur (Chaturvedi 2000, 38). Ancak hemen hemen her köşesi kutsal insanlarla dolu Hindistan'da Sai kelimesinin daha ziyade Müslümanlar için kullanılan bir ifade olduğunu söyleyebiliriz. Yaşının ilerlemesiyle adına eklenen 'Baba' kelimesi ise genel olarak yaşça büyüklere saygı amaçlı kullanılmasının yanında hem Müslüman hem Hindu asketikleri için Hindistan'da kullanılan bir kelimedir (Loar 2018, 476).

Sai Baba'nın Müslüman mı yoksa Hindu menşeden mi olduğu hususu özellikle yüksek kast Hindular için büyük önem taşır. Çünkü yüksek kast bir Hindu için Müslüman birine boyun eğmek onun tavsiye ve uyarılarına kulak vermek alçaltıcı bir durum olarak görülmektedir. ${ }^{4} \mathrm{Bu}$ yüzden onun menşeine meşruiyet kazandırmayı amaçlayan doğaüstü anlatılar dahi mevcuttur. Onun Brahmin bir aileden geldiğini bizzat Babanın kendisinin dile getirdiği bilgisine birçok eserde yer verilir (Rigopoulos 1993, 13). Sai Baba'nın ilerleyen yaşına kadar bu husustan bahsetmemişken son yıllarında iken yine Maharaştra eyaletine bağlı Evrengabad şehrinin Pathri köyünden yoksul Brahmin ailenin çocuğu olduğunu söylediği aktarılır (Warren 2009, 29). Sai Baba'nın 'Ben Pathri'li bir brahmindim sonra ailem beni bir fakîr'e verdi' dediği hatta buradan kendisini ziyarete gelenlerle sohbet ederken onlara Pathri'den bazı kimseleri sorduğu, bu kimselerle ilgili bazı bilgileri paylaştığını, ona Sai lakabını kazandıran ve sonraları müridi olan Mahlsapati iletmiştir (Narasimhaswami 1999, 148). Yine başka bir konuşması sırasında kendisinin Müslüman olduğunu 'Ben Müslüman kastındanım.' sözleriyle dile getirdiğine dair bilgiler bulunmaktadır (Warren 2009, 185).

Sai Baba’nın Pathri'li bir Brahmin ailenin çocuğu olduğunu Sathya Sai Baba da dile getirir. Ünü günümüzde Hindistan sınırlarını aşarak dünya çapında tapınakları olan, eklektik bir inanç sistemi diye tanımlayabileceğimiz Sathya Sai Baba Hareketinin kurucusu meşhur guru Sathya Sai Baba'nın, Şirdi Sai Baba'nın tanınmasında rolü yadsınamaz. 1926 senesinde dünyaya gelen Sathya Sai Baba'nın asıl adı Sathyanarayan Raju'dur. O, 14 yaşında iken ruhani bir tecrübe yaşayarak geçmiş hayatlarını hatırladığını, kendisinin tanrı Şiva ve Şakti olduğunu, şimdiki hayatının ikinci inkarnasyonu ve daha önce Şirdi Sai Baba olarak dünyaya geldiğini, üçüncü gelişinde ise Prema Sai adıyla inkarne olacağını iddia etmiştir (Kutlutürk 2018, 198-200).

${ }^{4}$ Hindularca Müslümanlara hitaben kullanılan Mleççha cahil, pis ve Yavana öteki, yabani gibi kelimeler bunun bariz birer örneğini teşkil eder (Kutlutürk 2019, 87-98).

Turkish Academic Research Review - Türk Akademik Araştırmalar Dergisi https://dergipark.org.tr/tr/pub/tarr 
Şirdi Sai Baba'nın doğumu ile ilgili mucizeleri de barındıran hikayelerin en renkli ve ayrıntılı versiyonunu Sathya Sai Baba anlatır. Kendisinin Şirdi Sai Baba inkarnasyonunda Pathri' de fakîr bir brahmin ailede dünyaya geldiğini ve ailesinin çok dindar birer Şiva adanmışı olduklarını aktarır. Bu dindar çiftin çocukları olmamıştır. Tanrı Şiva ve karısı Şakti bu çifti sınamak için dünyaya gelir ve testi geçen çifti Şiva üç çocukla müjdeler. En küçükleri yani Sai Baba ise tanrı Şiva'nın bizzat avatarası olacaktır (Ruhela 1997, 1-2). Bir zaman sonra çiftin gerçekten önce bir oğul sonra bir kızları olur. Karısı üçüncü çocuğa hamile iken Ganga Bhavaida dünya hayatından tamamen el etek çekme arzusuna kapılır. Asketik yaşam sürmek için evini terk ederek hac yoluna koyulur. Onu tek bırakmayan karısı Devagiriamma da peşinde yola çıkarlar. Ormanda doğum sancıları tutan Devagiriamma doğum yaparak çocuğu ormana bırakır. Sai Baba, Patil isimli bir Müslüman fakîr ve karısı tarafından bulunur (Chaturvedi 2000, 12-24). Bu iddialar bazı Şirdi Sai Baba taraftarlarınca kabul görürken birçoğu ise bu iddiaları asılsız kabul ederek Sathya Sai Babayı tamamen reddeder (McLain 2016, 187).

Sathya Sai Baba kadar ayrıntılı ve iddialı olmamakla beraber Şirdi Sai Baba'nın Pathri'li bir Brahmin ailenin çocuğu olduğu iddiası birçok eserde geçmektedir. Hatta bazı eserler Sai Baba'nın doğduğu evin kapı numarasına kadar bilgiler içerir (Ruhela 2015, 1-2).

$\mathrm{Bu}$ bilgilerin tarihsel bir gerçeklik taşımaktan son derece uzak oldukları aşikardır. Burada asıl amaç yukarıda da bahsi geçtiği üzere onun yüksek Hindu kastına mensup biri olduğunu savunma gayretidir. Sai Baba'nın Müslüman bir aileden geldiğini iddia edenler de mevcuttur. Bu anlatılardan biri şu şekildedir; Sai Baba Manvat'lı yoksul bir Müslüman ailenin çocuğu olarak dünyaya gelir (Munsiff 1939, 47). Babası ölünce annesi onu da yanına alarak gezgin bir dilenci yaşamı benimser. Sai Baba beş yaşında iken geldikleri Selu'da (bazı kaynaklarda Şelvadi) annesi, onu köyün sahibi Brahmin Gopal Rao Deşmuk’un yanına verir (Shepherd 1986, 6-10). Gopal Rao'nun Vekuşa adıyla meşhur bir guru olduğu dile getirilir. Bu bilginin doğru olamayacağını, anlatılarda adı geçen Gopal Deşmuk’un Sai Baba doğmadan önce vefat ettiğini bölgede yapılan araştırmalar ortaya koymuştur. (Kamath M.V., Kher V.B. 1991, 21). Zira Venkuşa'nın Venku Şah adlı bir sufi pir olabileceği de iddia edilmiştir (Warren 2009, 31). Dikkate şayan bir anlatıda da Sai Babanın kendisini bulan sufi fakîrin ölümünden sonra garip ve sırlı haller sergilemeye başladığından bahsedilir. Tapınağa gidip Kur'an okumakta, camiye gidip “Şiva Allah'tır, Rama Allah 'tır" demekte, her iki dinin mensuplarının da tepkisini çekmekteydi. Bunun üzerine annesi onu Selu’ya götürüp Gopal Rao’ya teslim etmiştir (Ruhela 2000, 19- 
20). Sai Baba 4-5 yaşlarına kadar Müslüman bir fakîrin yanında yetişmiş, beş yaşlarında iken fakîrin ölümünden sonra 16 yaşına kadar yanında kalacağı gurusuna verilmiştir.

Sai Baba'nın, gurusu Venkuşa'nın yanında yaklaşık 12 yıl kaldığı ve onun ölümünün ardından Şirdi’ye gitmek üzere Selu'dan ayrıldığı anlatılır. Burada da karşımıza mucizelerle bezenmiş bir anlatım çıkar. Venkuşa'nın diğer talebeleri Sai Baba'yı kıskanır ve ona bir tuğla firlatırlar Venkuşa ise tuğlayı kendine çevirir. Tuğlayı firlatan talebe oracıkta yere yığılıp ölür, diğerleri ise pişmanlıkla Venkuşa'ya yalvarırlar. Venkuşa Sai Baba’yı yanına çağırarak güçlerini ona aktarır ve kısır bir inekten süt getirmesini söyler. Sai Baba denileni yapar daha sonra ölen müridi de gurusunun ayağının altından aldığı tozu üzerine serperek diriltir. Gurusu son nefesini verirken ona Şirdi’ye gitmesini söyler (Rigopoulos 1993, 9-12). Hindu bir gurunun değil de Müslüman bir fakîrin himayesinde, onun müridi olduğunu dile getirenler de vardir (Warren 2009, 31-32).

Sai Baba'nın Şirdi'den önceki hayatına dair anlatılar bazı hususlarda birbirleriyle benzerlikler taşımakta yahut bu anlatılarda ortak bazı kişi ve olaylardan bahsedilmektedir. Sai Baba Müslüman bir aileden gelmekte ya da Müslüman bir aileye, sonrasında ise bir guru ya da fakîr'in yanına verilmektedir. Bu sayede onun her iki dinin mensuplarının yanında bulunduğu, her iki inancın kavram ve sembollerine, inanç ve ibadetlerine aşinalığ açıklığa kavuşturulmaya çalışılmaktadır. Bazısı için bu, ona Brahmin bir hüviyet vererek onu Hindulaştırma, onun Hindu kökenine meşruiyet kazandırarak İslami kavramlara dair bilgi ve uygulamalarını da açıklamaya yönelik bir çaba olarak değerlendirilebilirken, bazısı içinse onun Müslüman kökenini savunma ve ispat etme niteliğindedir.

Burada dikkati çeken önemli bir diğer husus da birçok eserde geçiyor ve genel kabul görüyor olmasına rağmen Sai Babanın İslami birikiminin 5 yaşına kadar oluştuğu bilgisinin gerçeklikten uzak oluşudur. Sadece dört ya da beş yaşına kadar Müslüman gibi yetişmiş daha sonra ise 16 yaşına kadar Hindu bir gurunun yanında, ondan eğitim almış birinin Müslüman kimliğinin bu kadar ön planda olması, onun hal ve hareketlerinde, giyim kuşamında Müslüman sufi özelliklerinin ağır basması akla yatkın değildir.

Onun söylemleri ve davranışları bizlere Sai Baba'nın her iki inancın mensupları ile münasebetinin bulunduğunu ancak özellikle tasavvufi İslam geleneğiyle bağının bilinenden daha derin olduğunu düşündürmektedir.

Turkish Academic Research Review - Türk Akademik Araştırmalar Dergisi https://dergipark.org.tr/tr/pub/tarr 
Kesin bir bilgi bulunmamakla birlikte Sai Baba'nın 1838 senesinde dünyaya geldiği kabul edilir. Hakkında kaleme alınan eserlerin birçoğu bu tarihte fikir birliği içerisindedir (Dabholkar 2018, 58-59; Kher 2000, 4). Bu tarihin hesaplanmasında Sai Babanın Şirdi'ye ilk geldiği tarih olan 1854 yılı baz alınır (Rigopoulos 1993, 36; Warren 2009, 31).

Buraya kadar bahsi geçen her husus Baba’nın konuşmaları sırasında elde edilen verilerden yola çıkarak öne sürülen hipotezler veya mucizelerle dolu mistik anlatılardan ibarettir. Bu bilgilerin kısıtlı ve kesinlikten uzak olmasının en temel nedeni olarak bizzat Baba'nın bu hususta takındı̆̆ı tavır gösterilebilir. Sai Baba’nın kendisine yöneltilen sorulara cevap vermediği veya bu konularda çelişkili konuştuğu görülür. Örneğin kendisine anne ve babası sorulduğunda babam Brahma annem ise Maya, yaşı sorulduğunda 500 yahut binlerce yıl gibi cevaplar verdiği aktarılır (Narasimhaswami 1999, 153).

Bu gibi cevaplar onun doğmadan dünyaya geldiği ve tanrı olduğunu iddia edenlerin delil olarak kullandığı argümanlardandır (Warren 2009, 83). Onun bu hususların önemsiz görmesi ve cevaptan kaçınması hem Hint asketiklerinin hem Müslüman fakîrlerinin ortak özelliklerinden biridir. Bu gibi bilgilerin önemsiz ve faydasız olduğunu, dünyevi hiçbir bağın kıymetinin olmadığını vurgulamıştır. Zaten Babanın kendisini ziyaret eden, müridi olmak isteyenlere de aynı anlayışla yaklaştığı görülür. Her kast ve dinden insanı ayrım gözetmeksizin müridi olarak kabul etmiştir.

\section{Şirdi’ye Gelişi}

Geçmişi, guru ya da mürşidi hakkındaki bilgiler bu kadar çeşitli ve çelişkili olan Sai Baba'nın Şirdi’ye ilk gelişinin 1854 yılında henüz 16 yaşındayken olduğu dile getirilir. Bu ilk gelişinde Sai Baba’nın köye sadece yiyecek ve tütünü için para dilenmek için girdiği, bunun dışında köyün etrafındaki ormanlık alanda dolaştığı, inzivaya çekilip çileci bir asketik yaşam sürdürdüğü bir nim ağacı ${ }^{5}$ altında çok zorlu meditasyon ve yoga hareketleriyle meşgul olduğu aktarılır (Dabholkar 2018, 21; Bharucha 1984, 2-3). Bu şekilde Şirdi’nin etrafındaki ormanlık alanlarda yaklaşık üç yıl geçirmiş arkasından bir yıllık bir süre için bu bölgeyi terk ederek kayıplara karışmıştır. Bu dönemde nereye gittiği bilinmeyen Sai Baba’nın bizzat kendi ağzından

\footnotetext{
${ }^{5}$ Nim ya da neem, Hinduizm'de kutsal kabul edilen ağaçlardan biridir. Hem dini-ruhani hem de tıbbi öneme sahiptir. Hindu mitolojisine göre nim ağacı, Deva'lar olarak bilinen ilahi varlıklar tarafından Dünya'ya dökülen ölümsüzlük iksiri Amrita'nın damlalarından doğmuştur. Neem, aynı zamanda Ana Tanrıça, Kali veya Durga'nın tezahürlerinden biri olarak tazim edilir ve Neemari Devi olarak tanrılaştırılır. https://neempedia.com/life-of neem/\#Sushruta A Vital Resource in Ancient Medicine and Mythology
} 
1857 Hint İsyanı ${ }^{6}$ sırasında Jhansi'li Rani Lakşmibai saflarında savaşta olduğunu söylediği dile getirilir (Ruhela 2015, 7; Warren 2009, 205).

Daha sonra 1858 yılında bir daha ayrılmamak üzere Şirdi'ye döndüğü kabul edilir. Şirdi’ye gelişinde 20 yaşlarında bir genç fakîr görünümündedir. Üzerinde kafni ${ }^{7}$ denilen Müslüman asketiklere özgü beyaz bir entari, başında aynı kumaştan hiç çıkarmadığı bir örtü, kısa bir asa, dilendiği sıvıları koyduğu bir teneke kap, tütün içmek için kullandığı kilden piposu ve ölümüne yakın kırılana kadar yanından hiç ayırmadığı tuğlasıyla etrafta dolaşırdı (Bharucha 1984, 5). Bu tuğlanın gurusu Venkuşa'ya atılan tuğla olduğu ve onun anısına yanında taşıdığı dile getirildiği gibi gurusu ya da mürşidinin türbesine ait olduğuna dair anlatılar da mevcuttur. Şirdi'ye ikinci gelişinde de yine nim ağacı altında ve ormandaki bir mağarada yatıp kalkan Şirdi Baba yiyecek için Şirdi ve civarındaki bölgelerde dolaşmıştır. Bu nim ağacının altında türbe olduğu yahut gurusunun mezarının bulunduğu da ortaya atılan iddialardandır (Pradhan 1988, 27).

Yaklaşık üç-dört yıl bu şekilde yaşamaya devam eden Sai Baba daha sonra Şirdi'nin içinde bulunan eski ve terkedilmiş bir camiyi kendine mesken edinmiştir (Rigopoulos 1993, 60-62). Caminin avlusundaysa hiç söndürmediği kutsal bir ateş yakar. Sözleri ve dualarında hem İslami hem de Hindu sembol ve öğeler yer alır. Ölene kadar bu camide yaşamış, dini faaliyetlerinin çoğunu burada gerçekleştirmiştir. Dwarakamai $^{8}$ adını verdiği bu caminin kapıları her din, inanç, cinsiyet ve kasttan insana açıtı (Warren 2009, 92).

Ölümünden sonra ondan geriye kalan birkaç eşyası Sai Baba inanırları açısından büyük önem taşır. Dwarakamai de onun adanmışı olan hacıların ziyaret yeri haline gelmiştir (Srinivas 1999a, 92).

${ }^{6}$ Hint topraklarının büyük bir çoğunluğunu otoritesi altında bulunduran İngiliz Doğu Hindistan Şirketi'nin askerlerinin büyük bir kısmını olușturan Müslüman ve Hinduların ayaklanması ile başlayan ve sivil halkında katılımı ile gelişen ayaklanma 1859 yılında kanlı bir şekilde bastırılmıștır. Hint Bağımsızlık mücadelesinin ilk adımı olarak kabul edilir. (Bu konuda daha ayrıntılı bilgi için bkz. Bender, 2016).

${ }^{7}$ Taraftarları Sai Baba'nın kafnisini o kadar önemserler ki bir anlatıya göre "Sai Baba kafnisini Muktaram adında bir adanmışa verdi. Kafni kirli olduğu için Muktaram onu yıkadı ve kuruması için Wada'ya (Dharamshala) koydu. Bundan sonra Muktaram, Baba'nın Darshanına gitti. Kaka Saheb Dixit Wada'da Kafni'nin kurutulmak üzere tutulduğu yerde Vamanrao vardı. Kafni'den bir ses geldi "Bakın, Muktaram Beni buraya getirdi ve baş aşağı astı." http://www.saibabaofindia.com/shirdi_sai_baba_kafni_cloth_rare_photos.htm

8 Dwaraka: Literal anlamda Açık kapı, Geçit anlamına gelir Tanrı Vişnu'nun avatarası Krişna'nın meskeni anlamında kullanılmaktadır, Mai; anne, bu iki kelimenin birleşimiyle kavrayıcı ve anne gibi koruyan, kapıları herkese açık olan Krişna'nın evi kastedilmektedir (Bharucha 1984, 12; Dabholkar 2018, 12).

Turkish Academic Research Review - Türk Akademik Araştırmalar Dergisi 
Her sabah dilenmek için Dwarakamai'den çıkarak belirli birkaç evden dilenerek topladığı yiyecekleri sadece insanlarla değil kedi, köpek, kuş, böcek vb. her tür hayvanla da paylaşmıştır (Munsiff 1939, 53; Pradhan 1988, 16). Yemek yerken asla tadını umursamadığı ve çok az yediği de aktarılan bilgiler arasındadır (Dabholkar 2018, 48; Warren 2009, 124). Hastalara topladığı otlarla, yılan zehri vb. malzemelerle ve dilenerek aldığı ucuz ilaçlarla yardımcı olur bu tedavilerin karşılığında ise asla para kabul etmezdi (Narasimhaswami 2004, 17; Pradhan 1988, 31; Shepherd 1986, 43-48).

Şirdi’nin o dönemde nüfusunun büyük çoğunluğu Hindulardan oluşmaktaydı. Müslümanlar ise nüfusun onda birlik kısmına tekabül ediyordu (Rigopoulos 1993, 60-61). Çoğunluğu Hindulardan oluşan bu bölgede Müslüman bir fakîr kılığında dolaşan Sai Baba’ya deli bir Müslüman asketiği gözüyle yaklaşıldığı hatta onun taşlanmış olduğu bile aktarılır (Parthasarathy 1997, 15).

Sai Baba kafnisi ve başına aldığı örtüsüyle camide sürekli yanar vaziyette olan ateşin başında otururdu. Bu ateş Hindular için kutsal kabul edilen Dhuni’yi ${ }^{9}$ sembolize ettiği gibi bu ateşi Hindistan'da meşhur olan bazı heterodoks Sufi ekollerle ilişkilendirenler de olmuştur. Meczuplar denilen bu sufiler sabah akşam sürekli yanar halde tuttukları ateşin başında zikretmeleri ile meşhurdurlar (Shepherd 1986, 19; Warren 2009, 65). Yine bu ateşin Parsilerin sürekli yaktıkları ateşi temsil ettiğini dile getirenlerde vardır. Günümüzde bu ateş halen daha yanmaya devam etmektedir.

Yaktığı dhuni'ye ek olarak caminin içinde çan da çaldırmıştı. Hintli sufilere özgü kafni'nin yanı sıra bir Hindu geleneği olarak kulaklarının delik olduğu ve bir Müslüman gibi sünnetli olduğu ve sakallarını tıraş etmediği bizlere ulaşan bilgiler arasındadır. Sai Baba bizzat kendi elleriyle adanmışları için yemekler hazırlardı. Sadece giyim kuşamı, dış görünüşü değil söz ve fiilleri de hem İslam hem de Hinduizm'e ait öğeleri bir arada barındırmaktaydı. Müslüman adanmışları için hazırladığı yemeklere helal et eklediği veya hayvan kesilirken bizzat dualar ettiği, bununla beraber Hindular için vejetaryen yemekler hazırladığı ve dağıttığı aktarılır (Bharucha 1984, 9-11; Dabholkar 2018, 204; Warren 2009, 61-62 ve 186-187).

Baba'nın, köy halkının dikkatini çekmesine sebep olduğuna inanılan mucizesi ise suyu yağa çevirme hikayesidir. Hindu bir dükkân sahibi sürekli gelip yağ isteyen Sai Baba'yı geri çevirir bunun üzerine o yağ yerine su kullanır, lambasının fitilleri mucizevi bir şekilde alev alır ve sabaha kadar yanar. Bu durum köylüler arasında büyük bir şaşkınlık yaratır. Onların nezdinde Sai Baba artık aklını kaybetmiş

${ }^{9}$ Dhuni: Asketikler tarafından çeşitli sebeplerle yakılan ve çoğunlukla devamlı yanar halde tutulan kutsal ateş (Lochtefeld, James G. 2002, 195). 
bir fakîr olmaktan ziyade mucizeler gösteren bir ermiştir (Dabholkar 2018, 28-29). Zamanla Sai Baba'yı ziyarete gelenler artmaya başlamış ve mucizeleri kulaktan kulağa yayılarak ününü daha uzaklara taşımıştır. Başlangıçta Sai Baba'nın takipçi ve adanmışlarının çoğunluğunu Müslümanlar oluşturmaktayken ününün artması ve gösterdiği mucizelerin yayılması ile Hindular başta olmak üzere Parsi, Hıristiyan, Sikh vb. her dinden ziyaretine gelenler, ondan yardım isteyip, medet umanlar görülmüştür. (Srinivas 1999a, 91-92).

1886 yılında ise çok ilginç bir olay gerçekleşir. Üç gün bedeninden ayrılarak ölü kaldığı iddia edilir. Bu üç günlük sürede Sai Baba, “Allah'a gidiyorum” diyerek derin bir Samadhi'ye ${ }^{10}$ girer ve tanriyla bir olarak ruhani yeni bir mertebeye ulaşır (Warren 2009, 33-34). Sai Baba yakın adanmışlarına üç gün içinde kendine gelmezse bedeninin gömülmesini vasiyet etmiştir (Bharucha 1984, 26). Bu tarihten sonra ise artık bu olağanüstü tecrübenin arkasından taraftarlarınca günümüzde hala devam ettiğine inanılan mucizeleri yeni bir boyut kazanmıştır.

Dünyevi hiçbir şeye önem vermeyen Sai Baba tütünü ve lamba yağının masrafı haricinde para dilenmemiş verilen yardımları kabul etmemiştir. Dakşina ${ }^{11}$ denilen parayı almaya ise çok sonraları başlamıştır. Kendisine gelen herkesten dakşina istemediği, her verilen parayı ve miktarı kabul etmediği, sadece Fakîrine (tanrıyı kastederek) borçlu olanlardan aldığını söylediği aktarılır (Narasimhaswami 2008, 23; Warren 2009, 118-119). Bazı adanmışlardan ceplerindeki son kuruşa kadar istediği, ceplerinde ne kadar para varsa bildiği, belirli ve gizemli anlamlar içeren miktarları istediğine inanılırdı. Bunun kerametini de en iyi Sai Baba'nın muhatabı anlayabilirdi. Bu durum onun bir mucizesi olarak kabul edilirdi. Topladığı paralar ise asla kendinde kalmaz, etrafındakilere dağıtırdı. Civardaki Hindu tapınaklarına, cami ve türbelere bu paralardan yardım gönderip, onları tamir ettirirdi (Pradha 1988, 36).

Sai Baba ölmeden önce kendisine bir halef seçmemiştir. "Üzülmeyin ben öldükten sonra kabrim yaşamaya, yegâne sı̆̆ınak olarak beni görenlerle konuşmaya devam edecek. Ben daima sizinle beraberim.” dediği aktarılır (Warren 2009, 203). Vefat edene kadar Dwarakamai diye isimlendirdiği camide yaşamıştır. 1918 yılında hastalanarak bir süre sonra yemek yemeyi bırakan Sai Baba yaklaşık 17 günlük hastalığın ardından dünyaya veda eder. Ölümü ile yeni bir sorun ortaya çıkar. Müslüman ve Hindu bütün müritleri Baba'nın defnedilmesi hususunda hemfikir

10 Samadhi: dıș dünya ile bağın tamamen koptuğu trans hali, yoga ve meditasyonda merhale olduğu gibi türbe anlamı da taşır (Jones, C.A., Ryan, D.J. 2007, 377-378).

${ }^{11}$ Dakşina: Rahib'e verilen bağış, hediye, ücret, guruya adak olarak verilen maddi şeyler (M. Williams 2008, 466).

Turkish Academic Research Review - Türk Akademik Araştırmalar Dergisi https://dergipark.org.tr/tr/pub/tarr 
olmuşlardır ancak Hindu mu yoksa bir Müslüman olarak mı son yolculuğuna uğurlanacağ 1 tartışma konusu olmuştur. İki grubun anlaşmazlığının çözülmesi için yerel yöneticinin hakemliğinde oylama yapılır ve çoğunluğun kararına göre yani Hindu geleneğe uygun olarak hareket edilir. Hindu tapınak mimarisine göre inşa edilen Samadhi Mandir'e defnedilir (Dabholkar 2018, 220). Bunu takip eden süreç içerisinde ise Sai Baba’nın ölümüne kadar bırakmadığı Müslüman kimliğinin giderek silikleştiği, Hindu bir karaktere büründüğü görülür (Srinivas 1999b, 253-255).

\section{Mucizeleri}

Şirdi Sai Baba'ya müritleri ve taraftarlarınca hastalara şifa verme, aynı anda birden çok yerde bulunma, salgın hastalıkları engelleme, havada uçmak, şeytan çıkarma, istediği an samadhiye girebilme, yoktan var etme, geleceği bilme ve kontrol etme, zihin okuma, insanların düşüncelerini kontrol edebilme, ölüleri diriltme gibi mucizeler atfedilir (Bu konuda ayrıntılı bilgi için bkz. Dabholkar, 2018; Narasimhaswami, 1999 ve 2008). Tanınmasında büyük payı olan, ona atfedilen sayısız mucizeden birkaçına değinmemizin konumuz açısından faydalı olacağı kanaatindeyiz.

Öncesinde de belirttiğimiz gibi Sai Baba Şirdi’ye geldiğinde insanlara topladığı otlarla, ucuz ilaçlarla hatta yılan zehriyle yerel bir doktor görevi görerek şifacı tabiplik yapıyordu. Sonraları ise artık bitkiler ya da ilaçlar ortadan kalkmış bunların yerini sürekli yanar halde tuttuğu kutsal ateşten(dhuni) elde ettiği kül(udhi) almıştır (Rigopoulos 1993, 68). Kendini ziyarete gelenlere para almaksızın bu külden vermiş, hastalar ağrıyan yerlerine, yaralarına bu külü sürerek ya da tüketerek şifa bulmayı ummuştur. Ziyarete gelenlere Şirdi'den ayrılırken muhakkak bu külden verilirdi. Bu külün her hastalığa, akrep ve yılan sokmalarına iyi geldiğine, salgınları önlediğine, bereket getirdiğine, nazardan koruduğu ve şans getirdiğine inanılıyordu (Pradhan 1988, 31; Swallow 1982, 132). Günümüzde de Şri Sai Baba Sansthan Trust hala bu külü ücretsiz olarak dağıtmaktadır. Hatta internet sayfaları üzerinden form doldurarak bu külü temin etmek mümkündür. ${ }^{12}$

Bazen şifa vermek için küle dahi ihtiyaç duymamıştır; Sai Babanın gözleri görmeyen bir adanmışın gözlerini sadece dokunarak açtığı gibi, bazı hastalıkları da adanmışından kendine geçirerek bertaraf ettiği, çok uzaktaki adanmışlarının

12 Hindu karakterli bu dernek Sai Baba'nın ölümünün ardından kurulmuştur. Sai Baba'nın Şirdi'deki kabri Mahasamadhi Mandir dahil birçok tesis, 1923 y1lından beri yayınlanan Sai Leela adlı dergiyle hizmet vermektedir. Ayrıntılı bilgi için web adresleri: https://www.sai.org.in/en 
yardımına zaman ve mekânı aşarak yetiştiği, başka bedenlerde göründüğü meşhur mucizeleri arasında sayllır (Dabholkar 2018, 31-45).

Onun ün kazanmasını sağlayan mucizelerin başında ise çocuksuz ailelerin çocuk sahibi olmalarını sağladığı inancı gelir. Özellikle erkek çocuk beklentisiyle insanlar Şirdi'ye akın etmiştir (Pradhan 1988, 35). İş, eğitim, para, sağlık vb. her konuda insanlar Sai Baba'dan medet umarak onun yanına geliyor, ondan yardım diliyorlardı. Mürit ve taraftarlarının işlerini kolaylaştırdığı kendisine gelip dua ederek yardım isteyenlerin eğitim ve iş hayatında olağanüstü sonuçlar elde etmelerini sağladığı aktarılır. Bunun Sai Baba'nın adanmışlarına özgü bir durum olarak nitelendirilemeyeceğini ifade etmemiz yerinde olacaktır. Hangi inanıştan olursa olsun kutsal kabul edilen kişiler hayattayken de öldükten sonrada çeşitli isteklerinin gerçekleşmesini arzu eden, sıkıntıları için çare arayan ziyaretçilerin akınına uğramaktadır. Nitekim ülkemizde de bunun örneklerini görmek mümkündür.

Bir diğer meşhur mucizesi bölgede süregelen kolera salgını sırasında öğ̈̈ttüğü unu köyün sınırlarına döktürerek köye salgının girişini önlemesidir. Bu salgından Şirdi'nin etkilenmemesinin sebebi olarak Sai Baba görülür (Bharucha 1984, 66-67; Dabholkar 2018, 1-4).

Birçok Hint asketiği tarafından meditasyon sırasında bedenlerini terk ederek başka alemlere gittikleri iddiası dile getirilir. Bu hususta Sai Baba'yı özel kılan ise çifte bilince sahip olması yani hem fiziksel bedeninde bilinci açıken aynı anda çok uzaklardaki olaylara da hâkim olabildiği iddiasıdır. Çok uzak yerlere ziyaretlerine dair hikayelerini kutsal ateşinin başında adanmışlarıyla paylaşmayı da ihmal etmez (Bharucha 1984, 15). Ateşi, hava olaylarını kontrol edebildiğine dair anlatılarda vardır. Şiddetli ve tehlikeli bir firtına sırasında Baba öfkelenir ve firtınaya durmasını emreder, mucizevi olarak firtına aniden kesilir (Narasimhaswami 1999, 110-111).

Sai Baba'nın adanmışlarına, kendi guruları veya Vişnu, Şiva, Hanuman gibi tapındıkları tanrıların şeklinde göründüğüne dair birçok hikâye aktarılır (Warren 2009, 129). Bu hikayelerden biri şu şekildedir; kendisini ziyarete gelen Brahmin kastından bir ziyaretçi tereddüte kapılarak bir Müslümanın önünde eğilip tazim etmek istemez. Bunun üzerine o, ziyarete gelen Brahmin'e Rama (Vişnu) olarak görünür. Brahmin de onun ayaklarına kapanarak af diler (Bharucha 1984, 27).

Bu hikâye birkaç farklı sebepten dikkat çekicidir. Bunlardan ilki ziyaretçinin onu Müslüman olarak nitelendirmesidir. Sai Baba'nın ise buna itiraz etmediği görülür. Bununla beraber Rama şeklinde görünerek Hindu bir kimliğe de bürünür. Baba'nın bu tavrının senkretik ve kuşatıcı bir dini yaklaşım olduğu

Turkish Academic Research Review - Türk Akademik Araştırmalar Dergisi https://dergipark.org.tr/tr/pub/tarr 
söylenebilir. Nitekim bazı düşünürler Baba'nın her iki dini kapsayıcı, senkretik bir inanca sahip olduğunu, bazıları ise monistik $^{13}$ bir anlayışla hareket ettiğini dile getirmektedirler. Hatta Sai Baba hareketi altında Hindu ve Müslümanları bir araya getirici bir akım amaçlayanların dahi olduğu aktarılır (McLain 2016, 197-199; Srinivas 1999b, 254).

Sai Baba sadece insanlara değil bütün varlıklara saygı ve nezaketle muamele etmenin önemini vurgulayıp sabrı tavsiye etmiştir. Genel olarak sakin ve merhametli olarak tasvir edilen Sai Baba'nın zaman zaman, özellikle kendisine itiraz edilmesi ya da karışılması durumunda öfke patlamaları geçirdiği, değişken bir ruh haline sahip olduğu aktarılır (Warren 2009, 81). Kendisinin deli sanılmasına da neden olan değişken ruh hali, adanmışlarınca onun kerameti olarak değerlendirilmiştir.

Adanmışlarına göre Sai Baba'nın konuşmaları literal olmaktan ziyade sembolizm içerir, bazen onun söylediklerini sadece belirli kişiler anlayabilir. Adanmışlarının rüyalarına girer ve şifreli mesajlar verir (Bharucha 1984, 84). Ölümünden sonra dahi adanmışlarının rüyalarına girerek onlara yol gösterdiği, onlarla konuştuğuna dair pek çok hikâye Sai Baba hakkında kaleme alınmış eserlerde kendilerine yer bularak bizlere ulaşmıştır (Ruhela 2015, 141-145).

Hikayeleri sadece bunlarla sınırlı değildir. O, kendisinin ve bazı adanmışlarının hatta keçi, kurbağa ya da kertenkele gibi etrafındaki hayvanların bir önceki hayatlarına dair hikayeler paylaşır. Sai Baba'nın Hindu olduğunu iddia edenlerin en önemli argümanlarından birini de oluşturan bu hikayeleri genellikle belirli bir konuda ibret vermesi ve ders çıkarılması için aktardığı görülür (Narasimhaswami 1999, 146-152). Hindu inanç sisteminin temel öğelerinden olan ve tekrar dünyaya gelme anlamına gelen hulul/samsara ve buna sebep olan günahların birikimi yani karma kavramları İslam dininin itikadî prensipleriyle çakışır. Sai Baba'nın bu kavramları dillendirmesi onun Müslüman olmadığının kanıtı olmasa bile Hinduizm'in etkisinde kalmaktan kurtulamadığının açık bir kanıtıdır.

\section{İbadetleri ve Ayinleri}

Sai Baba’nın görüş ve fiilleri dünyanın her yerinden insanları etkilemişse de bizzat kendisinin kaleme aldığı bir eser bulunmamaktadır. Hatta düzenli ve organize bir şekilde öğretisini anlattığı bir zaman yahut yerde olmamıştır. Özel bir zaman ve yerden ziyade yeri geldikçe, şartların gerektirdiği şekilde öğütlerde

\footnotetext{
${ }^{13}$ Monizm; hakikatin tekliğini ya da birliğini ifade eder. Hakikat tektir ve diğer her şey yanılsama yahut hakikatin birer tezahürüdür. Hindu gelenekte monizm denince akla ilk olarak Advaita (ikili olmayan, tek olan) Vedanta gelmektedir. (McDermott, 2005, 6143-6145)
} 
bulunmuştur (Bharucha 1984, 72). Şradda (iman) ve Saburi (sabır) onun en çok vurguladığı prensiplerdendir. Sai Baba bütün adanmışlarına tanrıya güçlü bir iman ve sabrı tavsiye etmiş, hikayeler anlatarak tavsiyelerde bulunmuştur (Pradhan 1988, 51).

Sai Baba’nın öğretilerinin ortopraksi yani doğru eylem temeline dayandığı dile getirilir. Sai Baba'ya göre kişinin Tanrıya ulaşmasında doğru eylemler sürekli ibadetlerden daha faydalıdır (Elison 2014, 157).

Şekilden ari metafiziksel bir tanrı inanışına sahip Sai Baba'nın hayatı boyunca bu prensibe uygun hareket ettiği görülür (Bharucha 1984,72). Her daim tanrıyı en çok Allah lafzıyla zikrettiği bilinen Sai Baba adanmışlarına kendi dinlerinin gereklerine göre ibadet ve dua etmelerini salık vermiş, bu hususta insanları serbest bırakmıştır. Namaza ses çıkarmamakla birlikte sürekli ve düzenli olarak yapılan rutin ibadetleri onaylamamış, sıcak bakmamıştır. Örneğin oruç tutmadı̆̆ı, başkalarının tutmasını da istemediği birçok eserde yer alır (Bharucha 1984, 10; Dabholkar 2018, 173; Ruhela 2015, 16-18). 'Yade hakk' (Hakkl Analım), 'Allah Malik' (Allah Sahibimizdir), 'Allah Vali Hai' (Allah Yardımcımızdır), 'Sabka Malik Ek' (Herkesin Sahibi Tek'tir), 'Sabur Sabur' (Sabır Sabır), lafızları sürekli dilinde olan Sai Baba adanmışlarına da zikir ve duayı tavsiye etmiş, 'Allah Accha Karega' (Allah iyi etsin) lafzıyla adanmışlarını kutsamıştır (Narasimhaswami 2008, 83; Warren 2009, 94).

Sai Baba insanların din değiştirmesine sıcak bakmamış, diğer din ve inanışlara hoşgörü ile yaklaşılmasını vurgulamıştır (Bharucha 1984, xi). Müslüman müritleriyle Fatiha'yı ezberden tekrar edip onların Kur'an okumalarını dinlerken Hindularla Ramayana, Bhagavadgita gibi kutsal metinleri okumuştur (McLain 2011, 24; Narasimhaswami 2004, 47). Muhatabının inancına uygun olarak tanrıdan bahsederken Ram (Tanrı Vişnu) ya da Allah diye hitap ettiği de aktarılan bilgilerdendir (Warren 2009, 87). Sanskrit bildiği hatta Sanskrit bilgisi ve Hindu metinlerine aşinalığı ile meşhur bir müridine kutsal metinlerden sorular sorduğu ve onun eksiklerini tamamlayarak bilgisinin derinliğini gösterdiği de ifade edilmektedir (Dabholkar 2018, 206-210; Narasimhaswami 2008, 78-79). Görüyoruz ki o her iki dini bilmekte ve her ikisine ait bazı ritüel ve uygulamaları yerine getirmektedir. Bu da onun hangi dine mensup olduğunu anlamayı daha da güçleştirmektedir.

Sai Baba'ya gelen Hindu adanmışları evlerinde tapındıkları tanrılarına ek olarak Sai Baba'ya da fotoğrafı ile tapınıyorlar, onu anarak işlerinin olmasını diliyorlardı. Zaten birçoğu için o, bizzat tanrının kendisiydi. Ancak Sai Baba'nın kendisine tapınılmasına ömrünün son yıllarına doğru izin verdiği, başlangıçta bu duruma çok karşı olduğu konusunda fikir birliği vardır. Kendisine ilk tapınanın aynı

Turkish Academic Research Review - Türk Akademik Araştırmalar Dergisi https://dergipark.org.tr/tr/pub/tarr 
zamanda ilk adanmışı olarak kabul edilen Mahlsapati olduğu dile getirilir (Pradhan 1988, 40-41). Cemaat olarak tapınma, onun adına düzenli puja ${ }^{14}$ ve artilerin $^{15}$ düzenlenmesi ise 1909-1910 yıllarına denk gelir. Sai Baba bu tarihlerden itibaren kendisine puja ve ârtilerin düzenlenmesine izin vermiştir (Babuji 1996, XVI-XVII).

Sai Babaya adanmış, günün dört vaktinde gerçekleştirilen ârtiler mevcuttur. Bunlar sabah vakti gerçekleştirilen Kakad Ârti, öğlen vakti yapılan Madhyahn Ârti, akşam yapılan Dhup Ârti ve gece yapılan Sej Ârti'dir (Babuji 1996, 1-61; Pradhan 1988, 40-50). Sai Baba, kendisine tapınılmasına müsaade etmiş ancak Kakad ve Sej ârtilerinin yaşadığı mescit içerisinde yapılmasına onay vermemiştir. Çünkü bu ârtiler sırasında sadece ilahiler okunan Madhyan ve Dhup ârtilerinin aksine tam tapınma gerçekleştirilir (Babuji 1996, XXV-XXVI). Bu ise Müslümanların hoş karşılamayacağı bir durumdur, Sai Baba'nın bu hususa hassasiyet göstererek böyle bir tavır takındığını kabul edebiliriz.

Yine Sai Baba'nın sufi bir gelenek olan $u r s^{16}$ törenlerine izin verdiği ve bu törenlerin düzenli kutlandığı aktarılır. Müslüman bir adanmışının Sai Baba’nın kerametiyle erkek çocuk sahibi olmasının ardından 1897 yılında başlattığı bu törenler uzun yıllar sadece İslami çerçevede kutlanmıştır. Hindu dini festivali Ramnavami ile yakın tarihlerde kutlanan urs 1912 yılından itibaren birleştirilerek Müslüman ve Hindu adanmışların birlikte kutladıkları bir törene dönüşmüş (Bharucha 1984, 9), Sai Baba'nın ölümünü takip eden süreç içerisinde ise urs niteliğini yitirerek tamamen Hindularca kutlanan bir tören haline gelmiştir (Dabholkar 2018, 34-35).

Günümüzde Şirdi’de kutlanan üç temel festival vardır. Bunlardan ilki yukarıda bahsi geçen Ramnavami (Mart-Nisan) ikincisi Guru Purnima (Temmuz) ${ }^{17}$, üçüncüsü ise Vijaya Dasami ${ }^{18}$ de denilen Düssehra'dır (Eylül-Ekim) (Şirdi festivalleriyle ilgili ayrıntılı bilgi için bkz. A. Williams, 2004). Guru Purnima tüm Hindularca kendi azizlerini anma günü olarak kutlanmaktadır. Bu tarih Sai Baba'nın gerçek doğum günü bilinmediği için kutlanmaktadır. Ancak onun reankarnasyonu

\footnotetext{
14 Puja: Bazı kutsal hece veya şiirler olan mantraların tekrarlanmasıyla yapılan bir ibadettir (Jones, C.A., Ryan, D.J. 2007, 336).

15 Ârti: Bir kandil ya da yağ lambasının tanrının heykeli, resmi, sembolü vb. önünde sallanıp, gezdirilmesi temelinde dualar ve ilahilerinde eşlik ettiği bir ibadettir (Lochtefeld 2002, 51).

16 Urs: Arapça dügün anlamına gelen urs, tasavvuf ehli liderlerin yani mürşidlerin vefat yıldönümlerinde özellikle türbelerinde yapılan dini törenleri ifade etmek için, genellikle Hindistan ve çevresinde kullanılan bir kavramdır (Warren 2009, 69).

17 Guru Purnima: Diğer Hint dinlerinde de kutlanan, ruhani lider ve Gurulara adanmış bir festivaldir. Purnima dolunay anlamına gelmektedir (Lochtefeld 2007, 267, 377).

18 Vijaya Dasami: Tanrı Rama'nın, şeytan kral Ravana'yı yenmesi şerefine kutlanan bir festivaldir (Lochtefeld 2007, 377).
} 
olduğu iddia edilen Sathya Sai Baba'nın, Şirdi Sai Baba'nın doğum tarihinin 28 Eylül olduğunu söylediği aktarılır. (Türker 2019, 40)

Pek çok farklı tanrı veya tanrıçaya adanmış tapınakta Sai Baba'nın resim ve heykellerini görebileceğimiz gibi dünyanın hemen her köşesinde bizzat Sai Baba'ya adanmış ve her geçen gün artan mandirler de bulunmaktadır (Ruhela 2015, 6). Sai Baba'nın, resim ve heykellerinin, kendisi üzerine yazılmış kitap ve makalelerin yanı sıra birçok kez filmi de çekilmiştir (Warren 2009, 25). Özellikle 1977'de Ashok V. Bhushan tarafından yönetilen "Shirdi Ke Sai Baba" adlı filmin Sai Baba'nın şöhretini başlatan film olduğu iddia edilmektedir. (Türker 2019, 40)

Sai Baba'nın tapınak ve kutsal mekanların haricinde, duvarlardan resmî kurumlara, ağaç altlarından araçlara hemen her yerde karşımıza çıkan resimleri ve her ebatta heykelleri asıl fotoğraflarındaki Müslüman fakîr imajından çok daha farklı bir manzara çizer (Swallow 1982, 133). O’nun Hintli bir Müslüman fakîri kuşamının aksine Hindu figür ve klyafetleriyle tasvir edildiği görülür. Müslüman Fakîrlerine özgü elbisesi ve başındaki örtü artık beyaz değil, Hindu bir asketik veya din adamına özgü safran rengidir. Eli Hint tanrılarında olduğu gibi bazı Hindu işaretlerini yapar vaziyette ve alnında yine Hinduizm'in çeşitli mezheplerine özgü motifler görülür. Heykelleri de turuncu renkte elbiselerle, çiçekler ve kutsal sembollerle bir Hindu tanrısı gibi bezetilir (Elison 2014, 24-25). Sai Baba, Hindular tarafından benimsenmiş olmakla beraber Müslümanlar tarafindan da halen hürmet görmektedir. Hindulara benzer bir şekilde Sai Baba'nın resim ve sözleri İslami motiflerle beraber kullanılmakta, kutsal gün ve gecelere dair mesajları süslemektedir (McLain 2011, 3435). Bununla beraber Sai Babanın eklektik söylem ve uygulamaları ise onun safi Hindu kökenden geldiğini ya da tamamıyla İslami geleneğe bağlı olduğunu iddia etmeyi imkânsız kılar.

\section{Sonuç}

Hint kıtası dini zenginliğin özgün bir örneği olarak tarih boyunca pek çok din, dini akım ve şahsiyete ev sahipliği yapmıştır. Sai Baba da Hindistan'ın sosyal, kültürel ve dini çeşitliliğinin sayısız örneklerinin meşhurlarından biridir. Bilinmezleri, mucizeleri, iki din arasında kendine has sentez ve uygulamalarıyla dinler arası etkileşim ve oluşumlara güzel bir örnek, dikkate değer bir figür, Hindistan'ın zengin asketik-mistisizm geleneği içinde kendine özgü bir yer kazanmayı başarmış senkretik bir dini şahsiyet olduğunu ifade edebiliriz.

Onun maddi dünyaya, mal mülk ve hatta aile hayatına ilgi göstermediği, sevgi, sabır hoşgörü ile kendini bilmeyi ve tanrıya ulaşmayı yegâne hedef addettiği

Turkish Academic Research Review - Türk Akademik Araştırmalar Dergisi https://dergipark.org.tr/tr/pub/tarr 
görülür. Bu tutumu da onun tasavvuf geleneğinin bir lokma bir hırka yaşamları ile hikayeleri günümüzde hala anlatılagelen diğer tasavvuf ehli kimselerden bir farkı olmadığını gösterdiği gibi dünyadan elini eteğini çekerek tek amaç olarak tanrıya ulaşmayı seçmiş Hindu asketiklerini de andırır.

Sai Baba kendisiyle ilgili sorulara dini menşei de dahil olmak üzere kayıtsız kalmayı tercih etmiştir. Ancak Müslüman ya da Hindu olduğuna dair soruları geri çevirirken ilgi çekerek taraftar toplama veya yeni bir dini görüş ortaya koyma gibi bir gayesi olmamış birçok söylem ve davranışında da bu durum kendini göstermiştir. Onun görüşleri kimileri için deli bir fakîrin sözleri kimileri içinse tanrının kelamıdır.

Sai Baba'nın vaaz ve söylemlerinde ise hem İslamiyet'e hem Hinduizm'e ait öğelere yer vermesi onun her iki dinin müntesiplerince sahiplenilmesini sağlarken onun dışlayııı bir tavır takınmamasının, kapsayıcı ve kuşatıcı dini prensiplerinin her din, yaş, cinsiyet ve kasttan insanın onu rehber ve öncü olarak görmesinde büyük payı vardir.

Her ne kadar Sai Baba'nın Müslüman kimliği günümüzde arka planda kalmış olsa da meşhur söz ve tavsiyeleri onun İslam'la bağını ortaya koymaktadır. Hatta vefatından yaklaşık on yıl öncesine kadar İslami kimliği çok daha belirgindir denilebilir. O, İslam dinine aşina olan bir Hindu'dan ziyade Hinduizm'e ait öğelere aşina, Hindu adanmışları olan bir Müslüman fakîr görünümündedir. Vefatından önceki son yıllarında kendisine tapınılmasına izin vermiş, karma, samsara gibi kavramları daha sık kullanmıştır. Ölümünü takip eden yıllarda Sai Baba'nın ünü Hindistan sınırlarını aşmış, Sathya Sai Baba'nın da katkısıyla dünya çapında tanınmıştır.

\section{Kaynakça}

Babuji, Sri Sainathuni Sarath (1996). Arati Sai Baba The Psalm Book of Sri Sai Baba Samadhi Mandir at Shirdi. India: Saiyana Books Saipatham Publications. Bharucha, Perin S. (1984). Sai Baba of Shirdi. Bombay: Shri Sai Baba Sansthan.

Bender, Jill C. (2016). The 1857 Indian Uprising and the British Empire. Cambridge: Cambridge University Press.

Chaturvedi, B. K. (2000). Sai Baba of Shirdi. New Delhi: Diamond Pocket Books. 
Dabholkar, Govind Raghunath (2018). The Wonderful Life And Teachings Of Shri Sai Baba: Shri Sai Satcharita. Trans. Nagesh Vasudev Gunaji. Shirdi: Shri Sai Baba Sansthan Trust.

Elison, William (2014). Sai Baba Of Bombay: A Saint, His Icon, And The Urban Geography Of Darshan. History of Religions, 54(2), 151-187. https://doi.org/10.1086/677808

Jones, C.A., Ryan, D.J. (2007). Encyclopedia of Hinduism. New York: Facts on File Inc.

Kamath M.V., V.B., Kher (1991). Sai Baba of Shirdi, A Unique Saint. Bombay: Jaica Publications.

Kher, V.B. (2000). Sai Baba: His Divine Glimpses. New Delhi: Sterling Publishers.

Kutlutürk, Cemil (2018). Hinduizm'de Avatar Inancı, Ankara: Otto Yayınları. (2019). Hint Düşüncesinde İslam Algıst. İstanbul: Dergâh Yayınlar1.

Loar, Jonathan (2018). From Neither/Nor to Both/and: Reconfiguring The Life and Legacy of Shirdi Sai Baba in Hagiography, International Journal of Hindu Studies, 22(3), 475-496. https://doi.org/10.1007/s11407-018-9246-0

Lochtefeld, James G. (2002). The Illustrated Encyclopedia of Hinduism, Volume 1. New York: Rosen Publishing.

McDermott, Robert A. (2005). Encyclopedia of Religion. Second Edition. Lindsay Jones(ed.). USA: Thomson Gale.

McLain, Karline (2011). Be United, Be Virtuous: Composite Culture and the Growth of Shirdi Sai Baba Devotion. Nova Religio, 15(2), 20-49. https://doi.org/10.1525/nr.2011.15.2.20

(2016) Shirdi Sai Baba as Guru and God: Narasimhaswami’s Vision of the Samartha Sadguru. The Journal of Hindu Studies, 9(2). 186-204. https://doi.org/10.1093/jhs/hiw016

Munsiff, Abdul Ghani (1939). Hazrat Sai Baba of Shirdi, Meher Baba Journal, 1(5), 46-56.

Narasimhaswami, H.H. (2008[1940]). Devotees' Experiences of Sri Sai Baba Part III-III. Chennai: All India Sai Samaj.

Turkish Academic Research Review - Türk Akademik Araştırmalar Dergisi https://dergipark.org.tr/tr/pub/tarr 
(2004). Life of Sai Baba (All Four Parts In One Composite Volume). Chennai: All India Sai Samaj Publication. (1999). Shri Sai Baba's Charters \& Sayings. Chennai: All India Sai Samaj Publication.

Parthasarathy, Rangaswami (1997). God Who Walked on Earth: The Life and Times of Shirdi Sai Baba. New Delhi: Sterling Publishing.

Pradhan, Rao Bahadur M.V. (1988). Shri Sai Baba of Shirdi A Glimpse of Indian Spirituality. Shirdi: Shirdi Sansthan of Shri Sai Baba.

Rigopoulos, Antonio (1993). The Life and Teachings of Sai Baba of Shirdi. New York: State University of New York Press.

Ruhela, Sathya Pal (1997). Divine Grace Of Shri Shirdi Sai Baba: Thrilling Experiences of Sai Devotees In The Post-Samadhi Period (1918-1997). New Delhi: Diamond Pocket Books.

(2015). Sri Shirdi Sai Baba: The Universal Master. India: Patridge Publishing.

(ed.) (2004). The Divine Life of Sri Shirdi Sai Baba. Sri Shirdi Sai Baba: The Unique Prophet of Integration içinde (17-32). New Delhi: Diamond Books.

Sharma, R.S. (2017). India's Ancient Past. New Delhi: Oxford University Press.

Shepherd, Kevin R.D. (1986). Gurus Rediscovered: Biographies of Sai Baba of Shirdi and Upasni Maharaj of Sakori. Cambridge: Anthropographia Publications.

Shinde, Kiran A. (2016). Planning For Urbanization In Religious Destinations: Insights From Shirdi, India. Planning Practice and Research, 32(2), 132151. https://doi.org/10.1080/02697459.2016.1198197

Sontheimer, Günther-Dietz (1989). Between Ghost and God: Folk Deity of the Deccan. Alf Hiltebeitel (ed.), Criminal Gods and Demon Devotees: Essays on the Guardians of Popular Hinduism içinde (ss. 299-337). New York: Sunny Press.

Srinivas, Smriti (1999a). Sai Baba: The double Utilization of Written and Oral Traditions in A Modern South Asian Religious Movement. Diogenes, 47(187), 88-99. https://doi.org/10.1177/039219219904718709 
(1999b). The Brahmin and The Fakir: Suburban Reliosity in Cult of Shirdi Baba, Journal of Contemporary Religion, 14 (2), 245-261

Swallow, D.A. (1982). Ashes and Powers: Myth, Rite and Miracle in an Indian GodMan's Cult. Modern Asian Studies, 16(1), 123-158. Great Britain: Cambridge University

Press. https://doi.org/10.1017/S0026749X0000072X

Türker, Merve (2019). Hint Kökenli Yeni Dini Hareketlerden Sai Baba Teşkilatı. (560074) Yayımlanmamış Yüksek Lisans Tezi. Süleyman Demirel Üniversitesi Sosyal Bilimler Enstitüsü. Isparta

Warren, Marianne (2009). Unravelling The Enigma Shirdi Sai Baba In The Light of Sufism. New Delhi: Bird Publications.

Williams, Allison (2004). Experiencing Sai Baba's Shirdi -A Guide. Shirdi: Saipatham Publications.

Williams, M. Monier (2008). A Sanskrit-English Dictionary. Varanasi: Indica Books.

https:/www.Sai.org.in/ Erişim Tarihi 01.02.2021

https://neempedia.com/life-of-

neem/\#Sushruta_A_Vital_Resource_in_Ancient_Medicine_and_Mytholo gy Erişim Tarihi 10.05.2021

http://www.saibabaofindia.com/shirdi sai baba kafni cloth rare photos.htm

Erişim tarihi 09.05.2021

Turkish Academic Research Review - Türk Akademik Araştırmalar Dergisi https://dergipark.org.tr/tr/pub/tarr 